\title{
KEBERDAYAAN MODAL SOSIAL KOMUNITAS PETANI PADI ORGANIK DI KELOMPOK TANI SUNDAMEKAR, DESA SUNDAWENANG, KECAMATAN SALAWU, KABUPATEN TASIKMALAYA
}

\author{
SHELLA RIZKIYANA*, IWAN SETIAWAN \\ Program Studi Agribisnis, Fakultas Pertanian, Universitas Padjajaran \\ Jalan Raya Bandung-Sumedang Km.21 Jatinangor Sumedang 45363 \\ *Email: Srizkiyana@gmail.com
}

\begin{abstract}
ABSTRAK
Salah satu faktor yang mempengaruhi fluktuasi dan inkonsistensi adopsi inofasi pertanian organik yaitu kurangnya aspek modal sosial pada suatu komunitas atau kelompok. Penelitian ini bertujuan untuk mengetahui keberdayaan modal sosial dalam komunitas petani padi organik, Bagaimana peran modal sosial dalam pengembangan padi organik dan faktor-faktor apa yang mempengaruhi modal sosial komunitas petani padi organik. Penelitian ini dilakukan di Kelompok Tani Sundamekar, Desa Sundawenang, Kecamatan Salawu, Kabupaten Tasikmalaya, Jawa Barat. Teknik pengambilan data dilakukan dengan cara wawancara kepada 50 orang petani yang merupakan anggota Kelompok Tani Sundamekar. Desain penelitian ini adalah kuantitatif deskriptif. Analisis data menggunakan regresi linier berganda dengan alat bantu SPSS version 20. Hasil penelitian menunjukan bahwa kolaborasi menjadi indikator yang paling eksis dan partisipasi menjadi indikator paling berperan bagi pengembangan pertanian organik, serta variabel faktor eksternal menjadi faktor yang dominan terhadap peran modal sosial. Aspek yang harus ditingkatkan yaitu aspek pasar, regenerasi petani, serta pengembangan teknologi informasi dan komunikasi.
\end{abstract}

Kata kunci: Keberdayaan, Modal Sosial, Komunitas Petani, Padi Organik

\section{ABSTRACT}

One of the factors that has affected the fluctuation and inconsistency of adoption of organic agriculture innovation is lack of social capital aspect in a community or group. This research aimed to know the empowerment of social capital in organic rice farmer community, how the role social capital in developing organic rice and what factors that was influencing towards social capital of organic rice farmer community. The research was conducted in Sundamekar farmer community, Sundawenang Village, Salawu District, Tasikmalaya Regency, West Java. The data collection technique was conducted by interviewing 50 peasants who were members of Sundamekar Farmer Group. The design of this research is quantitative descriptive. Data analysis using multiple linear regression with SPSS version 20 tool. The results of research shows that collaboration became the most exist indicator and participation became the most important indicator for the development of organic farming, and the external factor variable became the dominant factor to the role of social capital. Aspects to be improved are market aspect, regeneration of farmers, and development of information and communication technology.

Keywords: Empowerment, Social Capital, Farmer Community, Organic Rice

\section{PENDAHULUAN}

Pertanian organik berkembang secara cepat terutama di negara-negara Eropa. Amerika, dan Asia Timur (Jepang, Korea,
Taiwan). Secara historis, pengembangan pertanian organik di negara-negara maju dimulai tahun 1970-an. Secara riil, praktik pertanian organik modern telah dicoba- 
terapkan di Indonesia (terutama di Jawa Barat) sejak tahun 2000an, namun kebijakannya baru dilembagakan tahun 2010 melalui program Go Organic 2010. Salah satu daerah sentra produksi pertanian organik yang dijadikan sasaran program pengembangan Kementerian Pertanian adalah Kabupaten Tasikmalaya (Dinas Pertanian dan Tanaman Pangan Kabupaten Tasikmalaya. 2017).

Adanya kebijakan pertanian organik telah meningkatkan luas areal tanam dan areal panen di Indonesia dan di dunia pada umumnya. Hasil penelitian FIBL dan IFOAM (2016) menunjukkan bahwa total areal pertanian organik di dunia mengalami peningkatan yang signifikan dari 11,0 juta ha tahun 1999 menjadi 43,7 juta hektar tahun 2014. Pada kenyataannya, berbeda dengan di negara maju, penguatan kebijakan dan peningkatan luas areal tanam pertanian organik di Indonesia masih bersifat fluktuatif, baik di pusat maupun di daerah otonom.

Secara teoretis maupun praktis, seperti dalam proses difusi dan adopsi inovasi pada umumnya, adopsi pertanian organik juga dipengaruhi oleh banyak faktor (Sumardjo, 1999; Hanafie, 2010). Pertama, faktor sosial (minimnya SDM yang berkompetensi pertanian organik, baik petugas pembina, peneliti dan inspektur pertanian organik maupun pelaku usaha atau petani. Kualitas sumberdaya manusia (petani) yang dimiliki bidang pertanian saat ini sangat memprihatinkan (aging). Kedua, faktor ekonomi (proses kegiatannya memerlukan modal yang kuat, baik dalam bentuk uang tunai, bibit, pupuk organik, pestisida nabati, dan sebagainya). Ketiga, faktor teknologi (cara budidaya pertanian organik berbasiskan proses, sehingga dipandang lebih rumit daripada teknologi budidaya pertanian konvensional). Selain itu, tidak mudah bagi petani untuk mendapatkan dan berganti teknologi pertanian dari yang konvensional ke organik. Keempat, faktor kelembagaan (masih parsial dan sektoral, serta masih lemahnya pemihakan kelembagaan petani, daerah, dan pusat, baik karena masih bias pertanian konvensional, faktor ekonomi politik maupun akses administrasi).

Kabupaten Tasikmalaya merupakan salah satu sentra produksi padi organik di Jawa Barat. Dinas Pertanian Tanaman Pangan Kabupaten Tasikmalaya (2017) melaporkan bahwa perkembangan budidaya padi organik di Kabupaten Tasikmalaya masih mengalami fluktuasi. Meskipun luas tanam, total produksi dan produktifitas pertanian organik mengalami peningkatan pada tahun 2016, namun dalam periode 2012-2014 terlihat mengalami penurunan luas tanam. Peningkatan produksi beras organik yang signifikan terjadi pada periode 2015-2016. Hal ini terjadi karena adanya penambahan luas areal pertanian organik, baik karena faktor pemihakan kebijakan pemerintah daerah maupun terdorong oleh komunitas (kelompok tani, koperasi), jaringan pemasaran dan tingginya harga beras organik. Pertanyaannya adalah, mengapa fluktuasi, instabilitas dan inkonsistensi masih terjadi dalam pengembangan padi organik di Kabupaten Tasikmalaya? Apakah pertanian organik tidak cukup meyakinkan bagi para petani? Apakah petani kurang mendapat dukungan dari kelembagaan? Apakah tingginya harga beras organik hanya dinikmati oleh pelaku tertentu, sehingga kurang berbagi dengan petani? Apakah jaringan pemasaran dan input organik tidak terjangkau oleh para petani? 
Coleman (1990), Dasgupta (1999) dan Grootaert (2014) menyatakan bahwa ketidakstabilan, ketidakkonsistenan, ketidakpedulian dan ketidakterlibatan komunitas (termasuk petani, pekerja, buruh dan lainnya) dalam sebuah kegiatan sosial ekonomi atau program pembangunan terjadi karena lemahnya aspek modal sosial. Seperti halnya modal ekonomi, modal informasi, modal teknologi, modal alami dan modal institusi, modal sosial juga bersifat produktif. Sama halnya dengan pengembangan pertanian organik, yang bersifat produktif dan dapat meningkatkan keadaan lingkungan yang lebih baik, maka dalam hal pengembangan pertanian organik modal sosial sangat diperlukan. Rusydi Syahra (2003) menegaskan bahwa modal sosial akan menciptakan jaringan sosial yang memungkinkan adanya koordinasi dan komunikasi yang dapat menimbulkan rasa saling percaya di antara sesama manusia. Maka untuk itu apakah modal sosial masih eksis dalam keberlanjutan Kelompok Tani Sundamekar, adakah peran modal sosial dalam pengembangan pertanian organik, dan faktor apa saja yang mempengaruhi keberdayaan modal sosial di Kelompok Tani Sundamekar?

\section{METODE PENELITIAN}

Metode dalam penelitian ini menggunakan desain penelitian kuantitatif deskriptif dengan jenis metode survei.
Penelitian kuantitatif merupakan suatu penelitian untuk mengangkat fakta, variabel, ataupun fenomena-fenomena kemudian ditampilkan apa adanya pada waktu sekarang (Sugiyono, 2012). Metode deskriptif digunakan dalam penelitian ini untuk menjelaskan dan menafsirkan data secara sistematis sesuai dengan keadaan sebenarnya. Metode survei digunakan untuk mendapatkan data dari tempat tertentu yang alamiah (bukan buatan) dengan menyebarkan kuesioner dan melakukan teknik wawancara terstruktur kepada responden (Sugiyono, 2012). Penelitian ini menggunakan teknik purposif dalam penentuan tempat penelitian dan simple random sampling dalam menentukan responden di lapangan.

Data yang dikumpulkan dalam penelitian ini bersumber dari data primer dan data sekunder, Data primer diperoleh dari hasil observasi dan wawancara langsung terhadap responden. Data sekunder diperoleh dari berbagai sumber pustaka, seperti buku, internet, jurnal, dan lain sebagainya. Metode analisis yang digunakan dalam penelitian ini adalah analisis deskriptif menggunakan perhitungan Weighted Mean Score (WMS), dan analisis regresi linier berganda menggunakan komputer dengan program SPSS 20.0. Analisis deskriptif menggunakan perhitungan Weighted Mean score (WMS) adalah analisis yang 
menggunakan acuan pengkategorian data yang menggunakan pedoman pentabulasian data agar dapat menjawab penelitian satu dan dua (Riduwan, 2007). Analisis regresi linier berganda digunakan untuk melihat hubungan satu variabel dependen terhadap lebih dari satu variabel independen Sugiyono (2012).

\section{HASIL DAN PEMBAHASAN}

Desa Sundawenang yang merupakan pemekaran dari Desa Neglasari, secara administrasi merupakan salah satu desa di daerah Kecamatan Salawu Kabupaten Tasikmalaya, Provinsi Jawa Barat. Desa Sundawenang terbagi dalam 5 dusun, 9 Rukun Warga (RW), dan 37 Rukun Tetangga (RT). Desa Sundawenang memiliki karakteristik daerah topografi berbukit dengan luas wilayah 608,986 ha, dan berada pada ketinggian 900 meter di atas permukaan laut. Jumlah penduduk di Desa Sundaweng berjumlah 6.537 orang yang terdiri atas 3.263 laki-laki dan 3.274 perempuan.

Kelompok Tani Sundamekar berdiri sejak tahun 1987-an, dibentuk melalui program pemerintah. Pembentukan kelompok bertujuan untuk memudahkan pemerintah dalam melakukan program dan kegiatan-kegiatan bersama petani. Awalnya Kelompok Tani Sundamekar merupakan kelompok tani yang melakukan budidaya usahatani konvensional, namun pada tahun
2007 mulailah gencar program pertanian organik yang kemudian dijadikan program Dinas Pertanian Kabupaten Tasikmalaya khususnya pada komoditas padi, akhirnya Kelompok Tani Sundamekar dijadikan kelompok tani yang berbasis pertanian organik khususnya pada komoditas padi.

Karakteristik responden dalam penelitian ini sebagian besar termasuk kedalam kategori usia produktif $(\geq 59$ tahun) lulusan Sekolah Dasar (SD), tanggungan keluarga 4 orang, termasuk anggota aktif, luas lahan rata-rata 25-119 bata, lahan milik sendiri, pernah mengikuti penyuluhan, pengalaman bertani konvensional 13-15 tahun dan pengalaman bertani organik $>7$ tahun.

Eksistensi modal sosial yang ada di Kelompok Tani Sundamekar terdiri atas 8 indikator, yaitu: (1) Kepercayaan mendapatkan nilai $W M S$ 75,20\% (baik), kepercayaan antar petani dalam kelompok sangat baik karena segala sesuatu dilakukan secara terbuka baik yang berhubungan dengan kelompok atau terhadap sesama petani itu sendiri; (2) Jaringan mendapatkan nilai $W M S$ 70,96\% (baik), jaringan yang ada di Kelompok Tani Sundamekar terbagi dalam jaringan dengan Dinas Pertanian (jaringan formal) dan jaringan dengan mitra serta kelompok lain (jaringan informal); (3) Kolaborasi mendapatkan nilai WMS 80,27\% (baik), petani menyatakan bahwa kolaborasi yang 
ada di Kelompok Tani Sundamekar berupa bentuk kerjasama dengan kelompok, luar kelompok, dengan bandar dan mitra yang dalam kerjasamanya tidak ada kontrak tertulis; (4) Hubungan timbal balik mendapatkan nilai $W M S 78,53 \%$ (baik), hal ini sebagaimana dikemukakan oleh beberapa petani bahwa hubungan timbal balik yang ada di Kelompok Tani Sundamekar dilakukan hanya bertujuan untuk saling berbagi tanpa mengharapkan imbalan; (5) Norma mendapatkan nilai WMS 75,90\% (baik), sebagian besar petani mengatakan bahwa adanya norma dapat membuat kegiatan yang ada di dalam kelompok berjalan secara terstruktur sehingga memudahkan untuk mencapai tujuan, namun norma atau aturan yang ada di Kelompok Tani Sundamekar merupakan norma atau aturan tidak tertulis, walau demikian hal tersebut tidak menjadikan para petani berlaku seenaknya;

Komitmen mendapatkan nilai WMS 67,52\% (baik), sebagian petani merasa selalu berkomitmen untuk mendukung kegiatan yang ada di Kelompok Tani Sundamekar, namun pada aspek pemasaran petani mengakui bahwa mereka sering sekali menjual hasil panen kepada bandar dan tidak menjual kepada mitra, hal tersebut karena tawaran harga yang cukup berbeda; (7) Nilai (value) mendapatkan nilai WMS $76,90 \%$ (baik), walaupun masuk dalam kategori baik masih terdapat kendala yaitu nilai tambah yang dilakukan hanya sampai pada penggilingan gabah kering giling menjadi beras, belum sampai pada proses packaging yang dapat memberikan nilai tambah yang lebih, dan (8) Proaktif mendapatkan nilai 75,84\% (baik). Beberapa petani mengatakan, petani selalu berusaha mengikuti semua kegiatan baik yang ada di kelompok tani ataupun di luar kelompok tani, bersikap terbuka dan memberikan pendapat pada setiap kegiatan diskusi, memberikan masukan kepada kelompok agar tercapainya tujuan. Dengan ke 8 indikator yang masuk kategori nilai $W M S$ baik, maka dirasa keeksistensiannya indikator indikator tersebut masih ada dalam keberlanjutan Kelompok Tani Sundamekar (Tabel 1.).

Tabel 1. Eksistensi Modal Sosial

\begin{tabular}{|c|c|c|c|}
\hline No & $\begin{array}{c}\text { Eksistensi Modal } \\
\text { Sosial }\end{array}$ & $\begin{array}{c}\text { Nilai } \\
\text { WMS } \\
(\%)\end{array}$ & Keterangan \\
\hline 1 & Kepercayaan & 75,20 & Baik \\
\hline 2 & Jaringan & 70,96 & Baik \\
\hline 3 & Kolaborasi & 80,27 & Baik \\
\hline 4 & $\begin{array}{l}\text { Hubungan timbal } \\
\text { balik }\end{array}$ & 78,53 & Baik \\
\hline 5 & Norma & 75,90 & Baik \\
\hline 6 & Komitment & 67,52 & Baik \\
\hline 7 & Nilai & 76,90 & Baik \\
\hline 8 & Proaktif & 75,84 & Baik \\
\hline
\end{tabular}

Sumber: Data diolah, 2018

Peran modal sosial dalam pengembangan pertanian organik yang ada di Kelompok Tani Sundamekar terdiri atas 8 indikator, yaitu: (1) Meningkatkan kepercayaan mendapatkan nilai WMS $84,27 \%$ (Sangat Baik), beberapa petani menyatakan bahwa peran partisipasi di 
Kelompok Tani Sundamekar masih berperan besar terhadap pengembangan padi organik di Kelompok Tani Sundamekar, petani tidak pernah bosan untuk mengikuti kegiatan yang ada di kelompok walaupun kegiatan tersebut sering dilakukan seperti kumpul rutin dan lain sebagainya; (2) Mengembangkan jaringan mendapatkan nilai WMS 55,12\% (cukup). Hal ini menunjukkan bahwa indikator mengembangkan jejaring dirasakan kurang berperan oleh petani dalam pengembangan pertanian organik di Kelompok Tani Sundamekar;

Membangun kolaborasi mendapatkan nilai WMS 64,08\% (baik), sebagian besar petani menyatakan bahwa kolaborasi yang ada di Kelompok Tani Sundamekar, seperti saling berbagi ilmu pengetahuan antar petani, bekerjasama dengan mitra dan kelompok tani lain, dan bekerjasama dengan penyuluh atau Dinas Pertanian, namun kerjasama yang dilakukan dirasa kurang maksimal terutama dalam aspek pemasaran; (4) Menguatkan hubungan timbal balik mendapatkan nilai WMS 78,88\% (baik), hubungan timbal balik yang dirasakan oleh sebagian besar petani yaitu adanya kegiatan saling berbagi informasi, saling berbagi benih, saling berbagi pengalaman antar petani dan kegiatan saling bertukar informasi dengan peneliti dan mahasiswa pun dilakukan; (5) Menguatkan kepercayaan mendapatkan nilai WMS
$75,30 \%$ (baik), sebagian besar petani menyatakan bahwa kepercayaan petani sebagai anggota kelompok atau sebagai pengurus sudah ada karena kesadaran dan keyakinan masing-masing; (6) Menguatkan norma sosial mendapatkan nilai WMS $66,00 \%$ (baik). Contoh norma sosial yang ada di Kelompok Tani Sundamekar, yaitu tidak adanya peraturan tertulis namun petani mempunyai kominmen tinggi terhadap pengembangan pertanian organik di Kelompok Tani Sundamekar; (7) Meningkatkan Nilai (Value) masuk kategori baik dengan nilai $W M S 78,30 \%$, hal tersebut berarti nilai (value) masih berperan baik dalam pengembangan padi organik dan keberlanjutan Kelompok Tani Sundamekar, dan (8) Meningkatkan Sikap Proaktif mendapatkan nilai WMS 79,07\% (baik), Kegiatan proaktif yang terlihat yaitu aktifnya petani ketika tergabung dalam kegiatan diskusi, besarnya antusias petani ketika ada kegiatan. Peran modal sosial yang di Kelompok Tani Sundamekar dirasa masih berperan baik dalam pengembangan pertanian organik walapun masih terdapat satu indikator yang masuk kedalam kategori cukup (Tabel 2.). 
Tabel 2. Peran Modal Sosial

\begin{tabular}{|c|c|c|c|}
\hline No & $\begin{array}{l}\text { Peran Modal } \\
\text { Sosial }\end{array}$ & $\begin{array}{c}\text { Nilai } \\
\text { WMS (\%) }\end{array}$ & Keterangan \\
\hline 1 & $\begin{array}{l}\text { Meningkatkan } \\
\text { Partisipasi }\end{array}$ & 84,27 & Sangat Baik \\
\hline 2 & $\begin{array}{l}\text { Mengambangk } \\
\text { an Jejaring }\end{array}$ & 55,12 & Cukup \\
\hline 3 & $\begin{array}{l}\text { Membangun } \\
\text { Kolaborasi }\end{array}$ & 64,08 & Baik \\
\hline 4 & $\begin{array}{l}\text { Menguatkan } \\
\text { Hubungan } \\
\text { Timbal balik }\end{array}$ & 78,88 & Baik \\
\hline 5 & $\begin{array}{l}\text { Menguatkan } \\
\text { Kepercayaan }\end{array}$ & 75,30 & Baik \\
\hline 6 & $\begin{array}{l}\text { Menguatkan } \\
\text { Norma Sosial }\end{array}$ & 66,00 & Baik \\
\hline 7 & $\begin{array}{l}\text { Meningkatkan } \\
\text { Nilai (Value) }\end{array}$ & 78,30 & Baik \\
\hline 8 & $\begin{array}{l}\text { Meningkatkan } \\
\text { Sikap Proaktif }\end{array}$ & 79,07 & Baik \\
\hline
\end{tabular}

Sumber: Data diolah, 2018

Variabel bebas yang diduga berpengaruh terhadap variabel terikat adalah karakteristik petani, faktor eksternal, dan eksistensi modal sosial. Persamaan regresi yang digunakan adalah sebagi berikut:

$\mathrm{Y}=\mathrm{a}+\beta 1 \mathrm{X}_{1}+\beta 2 \mathrm{X}_{2}+\beta 3 \mathrm{X}_{3}+\mathrm{e}$

Keterangan :

$\mathrm{Y}=$ Peran Modal Sosial

a $=$ Konstanta

$\beta 1=$ Koefisien regresi dari variabel $\mathrm{X}_{1}$ (Karakteristik Petani)

$\mathrm{X}_{1}=$ Karakteristik Petani

$\beta 2=$ Koefisien regresi dari variabel $\mathrm{X}_{2}$ (Faktor Eksternal)

$\mathrm{X}_{2}=$ Faktor Eksternal

$\beta 3=$ Koefisien regresi dari variabel $X_{3}$

(Eksistensi Modal Sosial)

$\mathrm{X}_{3}=$ Eksistensi Modal Sosial

$\mathrm{e} \quad=$ standar eror

Faktor-faktor yang mempengaruhi keberdayaan modal sosial dapat dilhat dari hasil regresi liner berganda (Tabel 3).
Tabel 3. Output SPSS 20.0 Koefisien Korelasi Antar Variabel Correlations

\begin{tabular}{|c|c|c|c|c|c|}
\hline & & X1 & $\mathrm{X} 2$ & $\mathrm{X} 3$ & $\mathrm{Y}$ \\
\hline & $\begin{array}{l}\text { Pearson } \\
\text { Correlation }\end{array}$ & 1 & .148 & .201 & $.395^{* *}$ \\
\hline X1 & $\begin{array}{l}\text { Sig. (2- } \\
\text { tailed) }\end{array}$ & & .305 & .161 & .005 \\
\hline & $\mathrm{N}$ & 50 & 50 & 50 & 50 \\
\hline & Pearson & .148 & 1 & $.732^{* *}$ & $.827^{* *}$ \\
\hline $\mathrm{X} 2$ & $\begin{array}{l}\text { Sig. (2- } \\
\text { tailed) }\end{array}$ & .305 & & .000 & .000 \\
\hline & $\mathrm{N}$ & 50 & 50 & 50 & 50 \\
\hline & $\begin{array}{l}\text { Pearson } \\
\text { Correlation }\end{array}$ & .201 & $.732^{* *}$ & 1 & $768^{* *}$ \\
\hline X3 & $\begin{array}{l}\text { Sig. (2- } \\
\text { tailed) }\end{array}$ & .161 & .000 & & .000 \\
\hline & $\mathrm{N}$ & 50 & 50 & 50 & 50 \\
\hline & $\begin{array}{l}\text { Pearson } \\
\text { Correlation }\end{array}$ & $.395^{* *}$ & $.827^{* *}$ & $.768^{* *}$ & 1 \\
\hline$Y$ & $\begin{array}{l}\text { Sig. (2- } \\
\text { tailed) }\end{array}$ & .005 & .000 & .000 & \\
\hline & $\mathrm{N}$ & 50 & 50 & 50 & 50 \\
\hline
\end{tabular}

**. Correlation is significant at the 0.01 level (2tailed).

Sumber: Data diolah, 2018

Sebelum dilakukan uji regresi, terlebih dahulu dilakukan uji asumsi klasik. Uji asumsi klasik merupakan syarat yang harus dipenuhi sebelum dilakukan uji analisis statistik lainnya. Agar uji analisis statistik lainnya dapat dilakukan, maka harus dipastikan bahwa tidak ada asumsiasumsi yang dilanggar.

Untuk mengetahui faktor yang paling berpengaruh terhadap peran modal sosial, maka dihitung kontribusi masing-masing variabel. Untuk mengetahui kontribusi masing-masing variabel, maka terlebih dahulu dihitung nilai korelasi dengan hasil sebagai berikut.

Berdasarkan (Tabel 3), tampak bahwa nilai korelasi antara karakteristik petani 
dengan peran modal sosial sebesar 0.395, korelasi antara faktor eksternal dengan peran modal sosial sebesar 0.827 , korelasi antara eksistensi modal sosial dengan peran modal sosial sebesar 0.768. Selanjutnya melihat nilai koefisien regresi yang sudah terstandarisasi. Berdasarkan hasil analisis, dapat dihitung kontribusi masing-masing variabel sebagai berikut:

1. Kontribusi variabel karakteristik petani $(\mathrm{X} 1)=$ Standardized Coefficients regresi $\mathrm{X} 1$ dikali korelasi Y dan X1 $=0.250 \mathrm{x}$ $0.395=0.099(9.9 \%)$

2. Kontribusi variabel faktor eksternal $(\mathrm{X} 2)=$ Standardized Coefficients regresi $\mathrm{X} 2$ dikali korelasi Y dan X2 $=0.570 \mathrm{x}$ $0.827=0.471(47.1 \%)$

3. Kontribusi variabel eksistensi modal sosial $(\mathrm{X} 3)=$ Standardized Coefficients regresi X3 dikali korelasi $\mathrm{Y}$ dan $\mathrm{X} 3=$ $0.301 \times 0.768=0.231(23.1 \%)$

4. Totalnya sama dengan $0.099+0.471+$ $0.231=0.801(80.1 \%)$

Berdasarkan perhitungan di atas, diketahui faktor yang paling berpengaruh terhadap peran modal sosial adalah faktor eksternal (X2) karena memiliki kontribusi paling besar.

\section{KESIMPULAN}

1. Terdapat 8 kategori yang dirasa eksistensinya oleh petani dapat membantu keberlanjutan kelompok tani yaitu,: (1) Kepercayaan; (2)
Jaringan (Networking);

Kolaborasi; (4) Hubungan Timbal Balik; (5) Norma; (6) Komitmen; (7) Nilai; dan (8) Proaktif. Kedelapan kategori tersebut masuk dalam kategori baik dengan menggunakan perhitungan (WMS).

2. Peran modal sosial bagi pengembangan pertanian organik di Kelompok Tani Sundamekar yang masuk dalam kategori cukup/kurang berperan menurut perhitungan (WMS), yaitu indikator meningkatkan jejaring. Indikator yang masuk dalam kategori baik yaitu; (1) Membangun kolaborasi; (2) Menguatkan hubungan timbal balik;

Menguatkan kepercayaan;

Menguatkan norma social;

Meningkatkan nilai (value), dan (6) Meningkatkan sikap proaktif. indikator yang masuk dalam kategori sangat berperan, yaitu meningkatkan partisipasi.

3. faktor eksternal dengan indikator: (1) Bantuan input; (2) Penyuluhan; (3) Kelompok; (4) Pasar; dan (5) Kebijakan menjadi faktor dominan yang mempengaruhi modal sosial komunitas petani padi organik Kelompok Tani Sundamekar. 


\section{DAFTAR PUSTAKA}

Coleman, J. S. (1988). Social capital in the creation of human capital. American journal of sociology, 94, S95-S120.

Dasgupta, P., \& Serageldin, I. (Eds.). (2001). Social capital: a multifaceted perspective. World Bank Publications

Dinas Pertanian Kabupaten Tasikmalaya. Sumber Website: https://disperta.tasikmalayakab.go.id/ ((Diakses pada 2 Agustus 2017).

Ghozali, Imam. (2017). Ekonometrika Teori, Konsep Dan Aplikasi Dengan IBM SPSS 24. Semarang : Badan Penerbit Universitas Diponegoro

Grootaert, C. (Ed.). (2004). Measuring social capital: An integrated questionnaire (No. 18). World Bank Publications.
Hanafie, R. (2010). Pengantar ekonomi pertanian. Penerbit Andi

International Federation of Organik Agriculture Movements, Sumber Website: https://www.ifoam.bio/ (Diakses pada 2 Agustus 2017).

Riduwan. 2007. Rumus dan Data dalam aplikasi statistika. Bandung. ALFABETA

Sugiyono. 2012. Metode Penelitian Kuantitatif Kualitatif dan $R \& D$. Bandung: Alvabeta, CV

Susanto, D. (2010). Strategi peningkatan kapasitas modal sosial dan kualitas sumberdaya manusia pendamping pengembangan masyarakat Jurnal Komunikasi Pembangunan 8 (1). 